\title{
É POSSÍVEL A INCLUSÃO ESCOLAR SOB A LÓGICA CAPITALISTA? APONTAMENTOS SOBRE ALGUMAS REPRESENTAÇÕES DOS PROFESSORES DA REDE MUNICIPAL DE RONDONÓPOLIS-MT SOBRE INCLUSÃO*
}

\author{
Merilin Baldan (UFR) \\ Nivaldo Alexandre de Freitas (UFR)
}

\section{Introdução}

Ao tratarmos da educação numa perspectiva inclusiva, com vistas à superação de uma educação excludente, segregacionistas e integracionista/normalizadora, não podemos perder de vista os desafios e barreiras que esta perspectiva inclusiva enfrenta numa sociedade capitalista cujos processos formativos e educativos encontram-se sob uma ótica hegemônica.

Ao considerar a educação inclusiva como um direito é fundamental atentarmo-nos para os limites dessa inclusão diante da lógica do capital, assim como refletimos sobre os obstáculos pedagógicos que se colocam diante de sua construção. Esses limites e obstáculos, todavia, não devem servir para não empreendermos o nosso compromisso ético e político na construção de uma sociedade e de uma educação igualitárias, inclusivas e democráticas.

Nesse sentido, estamos cônscios das tensões, desafios e contradições, que são necessários reconhecermos e enfrentarmos nos âmbitos político e pedagógico, e sobre eles nos debruçamos a partir das representações e percepções dos professores da rede municipal de Rondonópolis, MT, em momento de formação continuada, de sensibilização para as questões da "Educação, inclusão e diversidade" e "Psicologia do desenvolvimento e escolarização". Esses foram os módulos de curta duração por nós ministrados e nos quais foi possível sensibilizar os professores para as questões da inclusão e fomentar discussões teóricas e reflexões qualificadas acerca da prática.

Assim, o presente capítulo tem como objetivo discutir as representações e percepções de professores da rede municipal de Rondonópolis

*DOI - 10.29388/978-65-86678-68-0-0-f.85-100 
(Mato Grosso) acerca da educação inclusiva. Considerando o espaço reflexivo da formação continuada de professores, foi possível compreender os modos de perceber e representar as experiências de educação inclusiva vivenciadas, ressaltando as boas práticas e os desafios que se colocam. É importante destacar as seguintes problemáticas que permearam as discussões e reflexões apresentadas neste capítulo: É possível a educação inclusiva? Por que a educação inclusiva é tão necessária? Quais são os desafios que se colocam diariamente para os professores? Existem práticas educativas que promovam a educação inclusiva?

A pesquisa envolveu estudos bibliográficos, documentais e empíricos, estes últimos realizados por meio de questionário eletrônico, para a obtenção e análise dos dados coletados. O referencial teórico está baseado em autores da perspectiva inclusiva de educação.

\section{A formação continuada de professores como espaço de reflexão qualificada}

É importante compreender que a formação de professores contempla momentos distintos, isto é, a formação inicial e a formação continuada e/ou em serviço. Iremos nos deter mais especificamente, neste texto, à formação continuada de professores.

Assentimos com Macedo (2005) quando ele nos revela que nós, profissionais da educação, embora sejamos profissionais das reflexões, nem sempre encontramos o tempo adequado para a pausa, a reflexão qualificada e a reorientação de nossas práticas educativas. Também concordamos com Candau et al. (2013) quanto à compreensão da formação continuada que tem a escola como locus de investigação e as experiências educativas dos professores como oportunidades para a reflexão qualificada.

Isto se dá, em especial, porque tal reflexão não decorre de processos espontâneos. São necessários a pausa, o olhar inquiridor e reflexivo sobre as nossas práticas educativas e sistematização do (re)conhecimento das boas práticas e dos desafios que nos acompanham no cotidiano escolar. É somente a partir da reflexão qualificada que podemos (re)orientar as nossas práticas, intervindo nos obstáculos que se colocam diante de nós e avançando sobre eles.

O objetivo da mediação desses processos formativos, no entanto, não deve ser visto como exclusivamente preparar melhor os professores considerados "despreparados", como o discurso apregoado no senso co- 
mum e promovido pelo discurso político nos apresenta. O conhecimento científico, a educação, o papel e a função da escola e as práticas sociais e educativas não são estáticas no tempo e no espaço, elas sofrem as transformações do mundo e sobre elas precisamos sempre nos atualizar. Longe de usar esse adágio para sucatear a formação de professores, tornando-a pragmática e utilitária, com redução dos fundamentos e arcabouço teórico-conceitual, é imprescindível o compromisso com a práxis educativa, refletindo e desenvolvendo práticas cada vez mais inclusivas e democráticas.

Tanto o tempo da formação inicial quanto o da formação continuada e/ou em serviço devem ser vistos como um continuum, comprometido com a formação, a inclusão e a democracia. As formações continuadas de professores, de tal modo, devem se colocar como espaços de sensibilização e de formação quando tratamos, respectivamente, de formações mais curtas, para público maior e mais amplo, e formações mais longas, com público reduzido e especializado. Sensibilização e formação, no entanto, devem ser pautadas pelo diálogo, pela práxis e pelo compromisso ético e político (CANDAU et al, 2013).

\section{A construção da educação inclusiva: historicidade e desafios atuais}

É importante destacarmos o caráter excludente da sociedade brasileira e consequentemente da educação ao longo de sua periodicidade (VEIGA, 2017; SAVIANI, 2013; CURY, 2002). Assim, podemos ter maior compreensão das dificuldades e desafios que se colocam para aqueles comprometidos com a inclusão e com a garantia de direitos. Não por acaso, também é fundamental a compreensão de que, ao abordar a inclusão, lidamos com tensões, conflitos e contradições conceituais, políticos e pedagógicos (GOÉS; LAPLANE, 2013).

Neste momento, pretendemos apresentar uma compreensão do processo de construção da educação inclusiva com a finalidade de contextualizar tanto os obstáculos (velhos e novos) como as conquistas e a necessidade da defesa da perspectiva inclusiva.

É possível depreender os processos de exclusão do diferente desde as sociedades mais remotas, seja pelo culto à perfeição, seja pelos modelos instituídos de "normal" e "anormal", bem como os processos de discriminação do "diferente". Aos diferentes, que fugiam da norma e da perfeição, vão sendo atribuídos estereótipos e estigmas que reforçam as ideias de sua 
exclusão e/ou eliminação (direta e indireta) ao lado de visões religiosas, filantrópicas e privatistas que vislumbravam o cuidado e o acolhimento. Em maior ou menor grau, os preconceitos, os estereótipos e os estigmas ainda permanecem na nossa sociedade, assim como as ideias de exclusão e segregação do "diferente" de modo geral e da Pessoa com Deficiência (PCD), de modo particular (NUNES; SAIA; TAVARES, 2015; NEVES; RAHME; FERREIRA, 2019).

A respeito da construção dos estereótipos e estigmas imputados à PcD e demais excluídos da escola (e da sociedade), é importante considerar como as nossas práticas sociais e educacionais estão imersas ora num modelo irreal (perfeição), ora num modelo homogeneizante. Tais processos são bastante nefastos, pois repercutem no processo de subjetivação e de formação das identidades e personalidades (FERREIRA; FERREIRA, 2013).

É por isso que, no século XIX, vão surgir as primeiras instituições de atendimento educacional especializado, ligadas à religião, à filantropia e ao setor privado, que vão acolher o "diferente"; aos poucos vão se instituindo no setor público, isto é, na escola pública regular, unidades especiais ou salas especiais para tal acolhimento, estruturando-se em modelos excludentes e segregacionistas. Se, por um lado, esta visão supera a eliminação direta e indireta dos sujeitos, os efeitos da segregação implicam também outras formas de exclusão (NUNES; SAIA; TAVARES, 2015; NEVES; RAHME; FERREI$R A, 2019)$.

No século $X X$, por sua vez, com o desenvolvimento das ciências (Medicina, Psicologia e Educação), vão emergindo teorias educacionais e ideias pedagógicas, relacionando desenvolvimento e aprendizagem, assim como fomentando práticas educativas institucionalizadas para o processo de escolarização da PcD. É ainda neste período em que se observa a obrigatoriedade da escolarização da PcD. Os avanços teóricos e pedagógicos, todavia, encerram a PcD em instituições (escolas e/ou salas) segregadas (NUNES; SAIA; TAVARES, 2015; NEVES; RAHME; FERREIRA, 2019).

Destarte, como arguem Ferreira e Ferreira (2013), a centralidade da biologia nas teorias desenvolvimentistas acabaram conformando os processos de desenvolvimento socioeducacional e operando uma redução da $\mathrm{PcD}$ à condição de deficiente. Por sua vez, Kassar (2013) também observa que desse processo decorrerá a sistematização da classificação e dos testes de prontidão para conformar os alunos a série correspondente ao seu desenvolvimento biológico e na constituição de salas homogêneas, inspeções sanitárias, etc. Não por acaso, também se nota a tentativa de biologização dos problemas socioeconômicos e educacionais dos demais excluídos da escola 
(e da sociedade), que atribuiu aos sujeitos a responsabilidade pelo seu fracasso ou sucesso.

O discurso do diferente e da sua eliminação (direta e indireta), todavia, vai permanecer por meio da difusão das ideias eugênicas que circularam na primeira metade do século $X X$ e cujos resquícios ainda permanecem na sociedade contemporânea.

A partir da segunda metade do século XX, com os discursos e teorias educacionais, bem como o fomento dos movimentos sociais, observarse-ão tanto críticas quanto repúdios às práticas excludentes e segregacionistas. Ademais, a partir da década de 1970, as discussões acerca do fracasso escolar de grande parte da população escolarizável ganham centralidade nos debates educacionais (NUNES; SAIA; TAVARES, 2015; NEVES; RAHME; FERREIRA, 2019).

Por sua vez, a partir da década de 1970, com as discussões acerca da globalização, fomenta-se cada vez mais a influência das agências multilaterais na condução das políticas dos países ditos subdesenvolvidos. Nesse processo, uma agenda internacional vai se instituindo, com a organização de conferências, declarações e acordos e, no campo educacional, vão se consolidando políticas públicas educacionais nos anos seguintes. É a partir desse período que dois modelos de escolarização/socialização vão disputar a hegemonia das políticas e das práticas pedagógicas da PcD.

A proposta de Integração e Normalização da PcD acaba por denotar uma perversidade pelo sujeito, uma vez que é atribuída a ele a responsabilidade pelo seu processo de adaptação à sociedade e à escola, ou seja, cabe a ele buscar tornar-se "normal". Por sua vez, a proposta de Educação Inclusiva tinha como espectro a inclusão no sentido mais amplo, isto é, abrangendo as PcD e os demais "excluídos" da escola. Esta proposta, todavia, previa um amplo processo de mudanças estruturais da escola e de mentalidade na sociedade e na educação, pois requer a responsabilidade de todos com o processo inclusivo (NUNES; SAIA; TAVARES, 2015; NEVES; RAHME; FERREIRA, 2019).

É deste modo que, na década de 1990, a perspectiva inclusiva foi a aposta da agenda internacional de educação e na proposição de políticas públicas em educação especial na perspectiva inclusiva, sob a influência das agências multinacionais.

A partir desse contexto é importante destacar que tivemos grandes avanços com a perspectiva inclusiva em educação, apesar de haver uma série de desafios a serem superados. Lembrando que a educação inclusiva como direito é fundamental para a construção da dignidade humana e da 
promoção da cidadania. A partir desse contexto é importante destacar que tivemos grandes avanços com a perspectiva inclusiva em educação, apesar de haver uma série de desafios a serem superados. Lembrando [E.S.1] [MB2] que a educação inclusiva como direito é fundamental para a construção da dignidade humana e da promoção da cidadania. A obrigatoriedade da escolarização da $\mathrm{PcD}$, assim como das demais pessoas, passou a ser realizada na rede pública de educação, com atendimento educacional especializado (AEE), bem como sala de recursos multifuncionais (SRM), como atendimento complementar e suplementar à educação regular, como práticas adaptativas do processo educacional para os professores das salas regulares e para o acompanhamento e suporte à PcD. Esses direitos conquistados em inclusão social, seus avanços e seus limites, e para seguirmos na luta por uma educação inclusiva, democrática e plural.(NUNES; SAIA; TAVARES, 2015; NEVES; RAHME; FERREIRA, 2019).

Adentramos o século XXI com a construção da educação em perspectiva inclusiva, cheia de tensões, contradições e desafios, mas com o reforço dos direitos reconhecidos. O debate acerca do direito à igualdade (universalidade) e do direito à diferença (especificações e ampliação de direitos) tornou-se essencial nesse período e pautou os caminhos da educação inclusiva no Brasil. ${ }^{1}$ Um marco desse momento é a elaboração da Política Nacional de Educação Especial na Perspectiva da Educação Inclusiva (2008).

Concordamos com Ferreira e Ferreira (2013) no que tange o compromisso com a perspectiva inclusiva na educação. Para além da reivindicação dos movimentos sociais para o reconhecimento da exclusão, da discriminação e do racismo e da exigência, ao mesmo tempo, da garantia de direitos e da reparação, é imprescindível a compreensão de mudanças mais amplas que envolvam a prática social e as mentalidades, assim como mudanças estruturais (barreiras físicas, por exemplo).

É importante dar destaque aos apontamentos presentes na literatura educacional quanto aos elementos necessários para a mudança das práticas (FERREIRA; FERREIRA, 2013; KASSAR, 2013; GOÉS, 2013; NEVES; RAHME; FERREIRA, 2019):

\section{- Reordenamento de todo o Sistema de Educação, nas três esferas, a fim de tornar a educação inclusiva materializada e trans- versal nos diferentes níveis de ensino e modalidades de educação;}

\footnotetext{
${ }^{1} \mathrm{~A}$ discussão referente ao direito à igualdade e ao direito à diferença pode ser conferida em Cury (2002), Saviani (2013) e Santos (1997; 2019).
} 
- Compreensão de que a inclusão não se encerra no acesso à escola/educação. É preciso atuar para que haja permanência e qualidade social;

- Compreender a educação e a inclusão como um direito e promover a cidadania de todos os sujeitos indistintamente;

- Ressignificar as compreensões entre educação, desenvolvimento e aprendizagem como forma de superar a visão de conformação da educação aos aspectos biológicos;

- Compreender as deficiências orgânicas das desigualdades socioeducativas e econômicas que têm produzido o fracasso escolar e, invariavelmente, excedido a demanda do AEE/SRM;

- $\quad$ Combater o preconceito e a discriminação à PcD e demais "excluídos" no interior da escola, em especial, combatendo os estereótipos e estigmas que visam à inferiorização e à exclusão;

- Compreender a importância de fomentar a formação no que tange os conhecimentos da educação especial (conhecimento das especificidades dos tipos e graus de deficiência) e da educação inclusiva (perspectiva mais abrangente de tratar os excluídos da escola);

- $\quad$ Promover as adequações na infraestrutura e nos móveis escolares;

- $\quad$ Fomentar uma melhor articulação e fortalecimento das parcerias entre os profissionais, agentes e instituições envolvidas no processo inclusivo, bem como garantir mediações qualificadas entre família e escola; professor da sala regular e professor do AEE/ SRM, entre pares (estudantes), bem como entre os agentes da escola e os demais serviços de saúde e assistência social;

- Garantir um número maior de profissionais para a educação, em particular, de professores para as salas regulares e para o $A E E / R M F$, a fim de atender a demanda da educação, da quantidade e variedade de atendimentos, garantindo maior tempo para as práticas adaptativas e acompanhamento especializado;

- $\quad$ Evitar a transformação do AEE/SRM em espaço de segregação e exclusão.

É imprescindível mencionar que, nos últimos anos, nos deparamos com um retrocesso na construção da educação inclusiva, a exemplo do Decreto no. 10.502/2020 (BRASIL, 2020). Esse Decreto retira a garantia da obrigatoriedade da matrícula na escola pública regular, deixando às famílias 
a "liberdade" de optarem por escolas especializadas de cunho privatista e filantrópico levando, portanto, a um retorno das práticas educativas segregacionistas. Devido à manifestação e pressão de vários setores da sociedade civil, o Supremo Tribunal Federal suspendeu por ora a eficácia do referido Decreto. ${ }^{2}$

Em vez de reafirmar os direitos garantidos, o referido decreto acaba por diluí-los e abre espaço para a negação da matrícula, fazendo recuar o enfrentamento dos desafios para a construção de uma escola (e sociedade) inclusiva e democrática.

Para avançarmos nas políticas públicas de educação, tanto na formação de professores quanto na educação inclusiva, defendemos o aumento de recursos para a educação, concursos públicos para atender as demandas das salas regulares e do atendimento educacional especializado, a promoção de mudanças na estrutura física das escolas e demais construções; acréscimos de recursos didáticos e pedagógicos para os processos de educação inclusiva, plano de carreira e condições salariais justas, e, ainda, o regime de dedicação exclusiva para o trabalho do professor, sendo $20 \mathrm{~h}$ para a prática pedagógica em sala de aula e $20 \mathrm{~h}$ para o seu planejamento e articulação com o AEE/SRM.

\section{Representações e percepções de professores sobre a experiência da educação inclusiva na rede municipal de Rondonópolis: a noção de inclusão}

Em seguida, analisamos as representações sobre inclusão dos professores da Rede Municipal de Ensino de Rondonópolis, MT, que participaram da formação continuada no segundo semestre de 2020.

\section{Método da pesquisa}

Este estudo é baseado na modalidade da pesquisa-ação. Nela, o pesquisador busca discutir e diagnosticar uma questão sobre a qual se deseja agir. Enquanto a intervenção é realizada há também a produção de conhecimento. Conforme Thiollent (1986, p.14), a pesquisa-ação pode ser definida como "um tipo de pesquisa social com base empírica que é concebida e realizada, em estreita associação com uma ação ou com a resolução de

\footnotetext{
${ }^{2}$ Maiores informações referentes à suspensão do decreto, visitar a página do Supremo Tribunal Federal, no seguinte endereço eletrônico: http://portal.stf.jus.br/noticias/verNoticiaDetalhe.asp?idConteudo=456419\&ori=1. Acesso em: 13 dez. 2020.
} 
um problema coletivo e no qual os pesquisadores e os participantes representativos da situação ou do problema estão envolvidos de modo cooperativo ou participativo".

O curso de formação continuada dos professores da Rede Municipal de Rondonópolis, em parceria com a UFR, contou com dez módulos. Em dois deles a questão da inclusão foi discutida: de forma menos específica, no módulo de Psicologia do desenvolvimento e escolarização e, de forma mais específica, no módulo Educação, Inclusão e Diversidade. Foram explicados aos professores cursistas os elementos da pesquisa e todos assinaram o Termo de Consentimento Livre e Esclarecido no início do trabalho.

Quanto à coleta de dados, foi elaborado e aplicado um formulário eletrônico vinculado ao módulo "Educação, Inclusão e Diversidade". Houve 104 respondentes que autorizaram o uso das suas respostas, de forma anônima, para os fins desta pesquisa.

\section{Resultados}

Devido à necessidade de delimitar o conteúdo deste capítulo, optamos por analisar as respostas dadas à primeira questão de nosso formulário, sendo que as demais serão objeto de futuras reflexões: $O$ que você entende por Inclusão?

Selecionamos, a seguir, algumas respostas acerca da representação dos professores sobre a noção de inclusão e tecemos comentários sobre alguns aspectos das respostas fornecidas. Os parâmetros adotados por nós para se pensar a definição de inclusão são os autores já mencionados neste capítulo e a Política Nacional de Educação Especial na Perspectiva da Educação Inclusiva, de 2008. Usamos os seguintes termos para descrever alguns aspectos dos respondentes: PI: Professor Iniciante; PE: Professor experiente; Área de formação; Pertencimento Étnico Racial; F: Feminino; M: Masculino.

\section{Discussão}

A grande maioria dos respondentes demonstrou compreender as questões relacionadas à inclusão, abrangendo os seus aspectos sociais, educacionais e políticos. Sem dúvida este é um dado importante a ser considerado.

Destaca-se a observação de alguns professores quanto às contradições presentes entre o direito proclamado e a sua materialização na prática social e educacional, como se pode ver na seguinte fala: 
Infelizmente a lei é linda, mas sua execução ainda não ocorre. Falta estrutura nas escolas e demais instituições públicas para bem atender as necessidades específicas de muitos; falta punição para quem ofende, denigre ou agride as pessoas por sua situação financeira, cor da pele, nacionalidade ou qualquer outro motivo absurdo. (PE, Pedagogia, Preto, F).

É possível depreender que parte das dificuldades da materialização desses direitos e da inclusão se deve ao fato de que o próprio campo educacional não articula a inclusão como um projeto comum de toda a comunidade escolar, isto é, envolvendo a construção e a consolidação da perspectiva inclusiva em seus projetos políticos pedagógicos. A esse respeito, um dos professores sinalizou: "Inclusão para mim levando para o âmbito escolar é quando a escola tem propostas desde o seu Projeto Político Pedagógico que possibilite o acesso, a permanência e a devida atenção, de todas as crianças na escola independente de sua cor, raça, gênero, orientação sexual ou deficiência. No âmbito geral é quando as políticas de governo têm em suas propostas a mesma intenção e atenção da escola, porém em maior abrangência." (PE, Pedagogia, Preto, F).

Considerando que as discussões e as reflexões acerca da "inclusão" não sejam novidades para os professores, é curioso constatar que, em uma questão aberta (“O que você entende por Inclusão?"), muitos respondentes tenham recorrido a sites e incorrido em plágio devido à necessidade de buscar o significado do termo/verbete/expressão "inclusão".

É preciso, ainda, sinalizar os efeitos de discursos romantizados, em especial, os que depositam no campo educacional a ideia de "amor". É preciso superar essa visão a fim de que possamos desenvolver práticas educativas intencionais e na perspectiva inclusiva. A respeito dessa questão, destacamos a resposta: "Todo ato de amor ao próximo. Aceitar as pessoas como elas são" (PE, Pedagogia, Preto, F). Ressalta-se que várias outras respostas foram dadas nesta mesma perspectiva.

Embora a literatura educacional dedicada à discussão da educação inclusiva observe as distinções das ideias pedagógicas relacionadas à exclusão, segregação, integração/normalização e inclusão, ainda subsistem no imaginário as correlações entre os termos inclusão e integração. A esse respeito, destacamos a seguinte resposta:

A inclusão é toda atitude, política ou tendência que pretende integrar as pessoas dentro da sociedade através de seus talentos e que, por sua vez, sejam correspondidas com os benefícios que a sociedade 
possa oferecer. Este tipo de integração deve ser realizado do ponto de vista econômico, educativo, político, etc. (PI, Pedagogia, Pardo, F).

Outra fala no mesmo sentido: "Acredito que, a inclusão é a integração absoluta de pessoas que possuem qualquer tipo de necessidade especial em sociedade" (PE, Pedagogia, Pardo, F). Como já foi apontado, alguns autores entendem que, na inclusão, a escola se transforma para receber estudantes com qualquer diferença, enquanto que, no modelo de integração, a escola recebe estudantes de minorias sociais, mas não se modifica para atendê-los, ou se modifica pouco, desde o ambiente físico até o currículo (CROCHÍK; CROCHÍK, 2008).

Relacionado ainda a uma compreensão imprecisa do que seja a educação inclusiva, obtivemos depoimentos que, além de conterem termos já superados, como "portadores de necessidades especiais", expressam a ideia de que a inclusão é apenas para $\mathrm{PcD}$, embora os marcos legais apontem que a ideia de inclusão se relaciona à observância de todas as singularidades:

Inclusão significa trazer novas oportunidades para as pessoas portadoras de necessidades especiais mesmo sabendo que é um processo que traz inúmeros desafios tanto para o aluno portador de necessidades especiais quanto para os professores que os recebem, mas este é o caminho que todos devem seguir e se adaptar, respeitando as leis que amparam esta modalidade e com isso quebrando-se tabus e abrindo caminhos na educação para todos (PI, Pedagogia, PNR, F).

Isso permite pensar que se esta professora não tem um estudante com deficiência em sua sala de aula, ela não necessita se haver com a educação inclusiva. Embora haja uma defesa da "educação para todos", percebe-se a falta de elementos teóricos para trabalhar com a proposta da educação inclusiva. Já esta definição apresentada por outra respondente se aproxima do conceito: "Inclusão é a inserção das pessoas que possuem algum tipo de necessidade em todas as esferas da sociedade, começando pelo meio educacional e tendo continuidade até o mercado de trabalho" (PE, Pedagogia, Branco, F). Aqui faltou a consideração de que todos possuem algum tipo de especificidade a ser considerada. Nesse sentido, a seguinte definição contempla o conceito na esfera escolar: "Inclusão acontece quando aceitamos os desafios diários, respeitando as diversidades e aprimorando os conhecimentos para levar a aprendizagem ao grupo de forma a compreender a limitação de cada aluno" (PE, Pedagogia, Preto, F). 


\section{Entre boas práticas inclusivas e desafios da construção da educação inclusiva}

É importante destacar que as tensões, contradições e desafios na construção da inclusão social e da educação inclusiva representam, em grande medida, problemas estruturais e políticos de uma sociedade capitalista e, portanto, se apresentam em diferentes esferas da vida, em diferentes tempos e espaços sociais.

Dentro da lógica do capital, a orientação para a racionalidade, a redução do custo, o aumento da eficiência e da produtividade, bem como a promoção da competitividade, tudo isso acaba ocasionando classes superlotadas, instalações e infraestruturas insuficientes e até mesmo precárias, quadro de profissionais da educação em número insuficiente e sem "uma adequada formação para conduzir práticas inclusivas" (LAPLANE, 2013; FERREIRA; FERREIRA, 2013).

Além de questionamentos (e inviabilização) da materialização dos direitos proclamados, uma vez que o direito é reformulado em novas legislações, instituem-se programas de aceleração, de correção de fluxo idadesérie, opção (desvirtuada) do ciclo e os processos de responsabilização individual (FERREIRA; FERREIRA, 2013).

É verdade que a educação inclusiva ainda não funciona plenamente e ela tem recebido muitas críticas por isso. Isso não deveria ser motivo para retroceder na história e anular seus avanços, como tenta fazer o Decreto no 10.502/2020, mas é sinal de que a efetivação da inclusão escolar (e social) depende não apenas de aspectos situados no interior da escola, mas também de elementos situados fora dela, ou seja, esta sociedade ainda convive com a tensão entre modelos educacionais para a mera adaptação do sujeito em um mundo com pouco sentido e uma educação capaz de dar sentido à vida e contribuir para uma sociedade justa e democrática.

Em nosso contexto no município de Rondonópolis, as questões estruturais não podem servir para omitir as especificidades da rede municipal na sua proposição quanto à educação inclusiva. A responsabilidade pela implementação, manutenção e fiscalização cabe à esfera municipal, assim como a garantia das condições para que a perspectiva inclusiva se materialize no sentido de superar o que já está previsto em lei.

Pudemos ver com os elementos desse texto que, no caso de Rondonópolis, muitos professores estão de acordo com a proposta de uma educação inclusiva e, principalmente, entendem o conceito fundamental de inclu- 
são. Todavia, parte dos professores ainda confunde conceitos ou os possuem de forma ainda pouco elaborada. Tais lacunas devem também ser objeto de preocupação e planejamento da secretaria municipal de educação.

É também de suma importância, para além das contradições, desafios e obstáculos que se colocam cotidianamente diante de nós, que possamos destacar as boas experiências em educação inclusiva empreendidas por professores da rede. Nesse sentido, algumas das definições sobre inclusão fornecidas pelos professores já dão mostras de compreensão teórica capaz de sustentar boas práticas.

A escola deve ser o espaço da pluralidade e da diversidade, um locus privilegiado para o combate à exclusão e à discriminação a partir da perspectiva de respeito às diferenças. Por isso, o modelo de educação inclusiva é importante para a luta por uma sociedade democrática, uma vez que este modelo permite a um sujeito o contato com a diferença e o respeito a ela desde a infância, de maneira que possa desenvolver-se sem se fechar para a diferença e com mais elementos para combater as inúmeras formas de preconceitos enraizados nesta sociedade.

Todavia, como nos lembra Frigotto (2020), temos muito pelo que lutar no Brasil para alcançar ainda alguns dos objetivos fundamentais da educação, como a erradicação do analfabetismo, a melhoria da estrutura material das redes de educação e efetivação de concepções pedagógicas emancipatórias. Infelizmente, a classe dominante tem como projeto barrar esse avanço, pois uma educação de qualidade para todos implica mudanças sociais.

Mesmo com todas as resistências, descasos e baixo investimento em educação, houve avanços, os quais estão sob risco devido à orientação antidemocrática que norteia parte das políticas públicas hoje, principalmente no âmbito do governo federal. Como dissemos, o debate acerca do direito à igualdade e do direito à diferença tornou-se essencial no Brasil, mas têm crescido também as tendências retrógradas contrárias a este debate. Trata-se, portanto, de um momento delicado de nossa história em que a luta por inclusão educacional e social não pode arrefecer.

\section{Referências}

BRASIL. Presidência da República. Decreto № 10.502, de 30 de setembro de 2020. Brasília, DF, 2020. Disponível em: http://www.planalto.gov.br/ccivil_03/_ato2019-2022/2020/decreto/D1050 2.htm. Acesso em: dez. 2020. 
BRASIL. Secretaria de Educação Especial. Política Nacional de Educação Especial na Perspectiva da Educação Inclusiva. Brasília, DF, 2008.

[Documento elaborado pelo Grupo de Trabalho nomeado pela portaria n. $555 / 2007$, prorrogada pela portaria n. $948 / 2007$, entregue ao ministro da Educação em 7 de janeiro de 2008]. Disponível em:

http://portal.mec.gov.br/arquivos/pdf/politicaeducespecial.pdf. Acesso em: dez. 2020.

CANDAU, Vera Maria et al. Educação em Direitos Humanos e formação de professores(as). 1. ed. SP: Cortez, 2013.

CROCHÍK, J. L.; CROCHÍK, N. Teoria crítica e educação inclusiva. InterMeio: Revista do Programa de Pós-Graduação em Educação, Campo Grande, MS, v. 14, n. 28 , p. 122-137, jul.-dez./2008.

CURY, Carlos Roberto Jamil. Direito à educação: direito à igualdade, direito à diferença. Cadernos de Pesquisa, São Paulo, n. 116, p. 245-262, 2002. Disponível em: http://www.scielo.br/pdf/cp/n116/14405.pdf. Acesso em: 12 fev. 2019.

FERREIRA, Maria Cecília C.; FERREIRA, Julio R. Sobre inclusão, políticas públicas e práticas pedagógicas. In: GOÉS, Maria Cecília Rafael de; LAPLANE, Adriana Lia Friseman de (ORG). Políticas e Práticas de Educação Inclusiva. 4. ed. rev. Campinas, SP: Autores, 2013.

FRIGOTTO, G. Empresários mais ricos do Brasil: a ignorância, o cinismo e a ganância que matam. Espaço e Economia: Revista brasileira de geografia econômica, Ano IX, n. 17, 2020. DOI: 10.4000/espacoeconomia.10852.

GOÉS, Maria Cecília Rafael de; LAPLANE, Adriana Lia Friseman de (Orgs.) Políticas e Práticas de Educação Inclusiva. 4. ed. rev. Campinas, SP: Autores, 2013. . Desafios da inclusão de alunos especiais: a escolarização do aprendiz e sua constituição como pessoa. In: GOÉS, Maria Cecília Rafael de; LAPLANE, Adriana Lia Friseman de (Orgs.) Políticas e Práticas de Educação Inclusiva. 4. ed. rev. Campinas, SP: Autores, 2013. 
KASSAR, Mônica de C. M. Matrículas de crianças com necessidades educativas especiais na rede de ensino regular: do que e de quem se fala? In: GOÉS, Maria Cecília Rafael de; LAPLANE, Adriana Lia Friseman de (Orgs). Políticas e Práticas de Educação Inclusiva. 4. ed. rev. Campinas, SP: Autores, 2013.

LAPLANE, Adriana Lia Friseman de. Notas para uma análise dos discursos sobre inclusão escolar. In: GOÉS, Maria Cecília Rafael de; LAPLANE, Adriana Lia Friseman de (Orgs.) Políticas e Práticas de Educação Inclusiva. 4. ed. rev. Campinas, SP: Autores, 2013.

MACEDO, Lino de. Ensaios Pedagógicos: como construir uma escola para todos. Porto Alegre: Artmed, 2005.

NEVES, Libéria Rodrigues; RAHME, Monica Maria Farid; FERREIRA, Carla Mercês da Rocha Jatobá. Política de Educação Especial e os Desafios de uma Perspectiva Inclusiva. Revista Educação \& Realidade. v. 44, n. 01, 2019. Disponível em: https://www.scielo.br/pdf/edreal/v44n1/2175-6236edreal-44-01-e84853.pdf. Acesso em: 12 fev. 2019.

NUNES, Sylvia da Silveira; SAIA, Ana Lúcia; TAVARES, Elizete. Educação inclusiva: entre a história, os preconceitos, a escola e a família. Psicologia: Ciência e Profissão, 2015, n. 35, v. 4. Disponível em: https://www.scielo.br/pdf/pcp/v35n4/1982-3703-pcp-35-4-1106.pdf. Acesso em: 12 fev. 2019.

SANTOS, Boaventura de Souza. Por uma concepção Multicultural dos Direitos Humanos. Lua Nova. n. 39. 1997. Disponível em: https://www.scielo.br/pdf/ln/n39/a07n39.pdf. Acesso em: 12 fev. 2019.

SANTOS, Boaventura de Souza; MARTINS, Bruno Sena. O pluriverso dos direitos humanos: a diversidade das lutas pela dignidade. BH: Editora Autêntica, 2019.

SAVIANI, Dermeval. Vicissitudes e perspectivas do direito à educação no Brasil: abordagem histórica e situação atual. Educação e sociedade. v.34. n.134, jul./set. 2013. Disponível em:

https://www.scielo.br/pdf/es/v34n124/06.pdf. Acesso em: 12 fev. 2019. 
THIOLLENT, M. Metodologia da pesquisa-ação. São Paulo: Cortez, 1994.

VEIGA, Cynthia Greive. Discriminação social e desigualdade escolar na história política da educação brasileira (1822-2016): alguns apontamentos.

Hist. Educ., Santa Maria, v. 21, n. 53, p. 158-181, dez. 2017. Disponível em: https://www.scielo.br/pdf/heduc/v21n53/2236-3459-heduc-21-5300158.pdf. Acesso em: 12 fev. 2019. 